\title{
SAÚDE MENTAL E EDUCAÇÃO: TRAJETÓRIA DE ESCOLARIZAÇÃO DOS USUÁRIOS DE UM CENTRO DE ATENÇÃO PSICOSSOCIAL
}

\author{
MENTAL HEALTH AND EDUCATION: \\ SCHOOLING TRAJECTORY OF USERS OF A \\ PSYCHOSOCIAL CARE CENTER
}

\section{SALUD MENTAL Y EDUCACIÓN: TRAYECTORIA DE LA ESCOLARIZACIÓN DE LOS USUARIOS DE UN CENTRO DE ATENCIÓN PSICOSOCIAL}

Ioneide de Oliveira Campos

Yasmim Bezerra Magalhães ${ }^{2}$

\begin{abstract}
Como citar este artigo: Campos IO, Magalhães YB. Saúde mental e educação: trajetória de escolarização dos usuários de um Centro de Atenção Psicossocial. Rev baiana enferm. 2020;34:e34925.

Objetivo: descrever e analisar a experiência dos usuários de um serviço de saúde mental acerca de suas trajetórias de escolarização, assim como o resgate do ensino por meio da Educação de Jovens e Adultos. Método: pesquisa descritiva e analítica, de abordagem qualitativa, realizada com usuários que frequentavam a Educação de Jovens e Adultos, os quais foram entrevistados. Posteriormente, seus discursos foram categorizados e analisados. Resultados: predominaram, na argumentação dos participantes, as interrupções com o contato escolar e a ausência de suporte social e familiar, que os impediu de alcançar suas metas iniciais de realização, as quais precisaram ser adaptadas ou substituídas. As motivações para o retorno à escolarização consideraram a entrada de novos agentes de cuidado, a busca pela autonomia e o prazer em desenvolver habilidades e expressão pela arte. Conclusão: as trajetórias narradas foram atravessadas por rupturas e perdas de projetos de vida, incluindo a educação. As motivações para o retorno à escolarização apareceram como busca pela autonomia. A Educação de Jovens e Adultos surgiu como espaço de experimentação, de novas escolhas e de construção de vínculos afetivos e sociais.
\end{abstract}

Descritores: Educação. Saúde Mental. Autonomia. Aprendizagem. Serviços de Saúde Mental.

Objective: to describe and analyze the experience of users of a mental health service about their schooling trajectories, as well as the rescue of teaching through Youth and Adult Education. Method: descriptive and analytical research, with a qualitative approach, conducted with users who attended Youth and Adult Education, who were interviewed. Subsequently, their discourses were categorized and analyzed. Results: interruptions with school contact and the absence of social and family support predominated in the participants' arguments, which prevented them from achieving their initial goals, which needed to be adapted or replaced. The motivations for the return to schooling considered the entry of new care agents, the search for autonomy and the pleasure in developing skills and expression by art. Conclusion: the trajectories narrated were crossed by ruptures and losses of life projects, including education. The motivations for the return to schooling appeared as a search for autonomy. The Youth and Adult Education emerged as a space for experimentation, new choices and the construction of affective and social bonds.

Descriptors: Education. Mental Health. Autonomy. Learning. Mental Health Services. Terapeuta Ocupacional. Docente da Universidade de Brasília. Brasília, Distrito Federal, Brasil. ioncampos20 I6@gmail.com. https://orcid.org/0000-0002-6803-2725.
Psicóloga. Universidade de Brasília. Brasília, Distrito Federal, Brasil. https://orcid.org/0000-0002-06 | 4-5644. 
Objetivo: describir y analizar la experiencia de los usuarios de un servicio de salud mental sobre sus trayectorias escolares, así como el rescate de la enseñanza a través de la Educación de Jóvenes y Adultos. Método: investigación descriptiva y analítica, con un enfoque cualitativo, realizada con usuarios que frecuentaban la Educación de Jóvenes y Adultos, que fueron entrevistados. Más tarde, sus discursos fueron categorizados y analizados. Resultados: las interrupciones con el contacto escolar y la ausencia de apoyo social y familiar predominaron en los argumentos de los participantes, lo que les impidió alcanzar sus objetivos iniciales, que fueron adaptados o reemplazados. Las motivaciones para el regreso a la escolarización consideraron la entrada de nuevos agentes de atención, la búsqueda de la autonomía y el placer en el desarrollo de habilidades y expresión por arte. Conclusión: las trayectorias narradas fueron atravesadas por rupturas y pérdidas de proyectos de vida, incluida la educación. Las motivaciones para el regreso a la educación aparecieron como una búsqueda de autonomía. La Educación de Jóvenes y Adultos surgió como un espacio para la experimentación, nuevas opciones y la construcción de lazos afectivos y sociales.

Descriptores: Educación. Salud Mental. Autonomía. Aprendizaje. Servicios de Salud Mental.

\section{Introdução}

A atenção psicossocial adota uma concepção de cuidado ancorada na reforma psiquiátrica (RP) brasileira, movimento social que surgiu nos anos 1970, com as denúncias e críticas às instituições de violência, os grandes manicômios, em um cenário de redemocratização e luta contra a ditadura ${ }^{(1)}$. A RP brasileira constituiu-se como uma política pública de saúde mental nos últimos anos e representou a mudança de paradigma assistencial, para um modelo psicossocial que teve como proposta a constituição de um novo lócus de intervenção no campo das relações da sociedade com a loucura, transformando-as. Isso vem ocorrendo por meio de formulações das políticas e estratégias de inclusão social dos sujeitos, processo ético de inclusão, solidariedade e cidadania $^{(2)}$, no contexto do Sistema Único de Saúde (SUS).

Os Centros de Atenção Psicossocial (CAPS), serviços estratégicos dessa proposta, promovem a reabilitação psicossocial. Esta compreende um conjunto de estratégias direcionadas a aumentar as possibilidades de trocas e valorização do sujeito e o seu contexto nos diferentes eixos de vida - moradia, trabalho, lazer $^{(3)}$ e educação. O objetivo da reabilitação psicossocial é gerar autonomia mediante a oferta de cuidado ampliado, de caráter inclusivo, que necessita articular a participação de instituições de amparo e proteção social na garantia dos direitos sociais e no exercício da cidadania dos usuários ${ }^{4}$, em uma perspectiva intersetorial.

É neste sentido que o campo da saúde mental, ao objetivar a inclusão das pessoas em sofrimento psíquico na sociedade, vem construindo um diálogo intersetorial entre a política de saúde mental e a educação, por meio de discussões ainda incipientes. Na III e IV Conferências Nacionais de Saúde Mental, a Educação de Jovens e Adultos (EJA) foi evidenciada como estratégia inclusiva. Nesses eventos, reafirmou-se a necessidade de diálogos entre esses campos ${ }^{(5)}$. É importante mencionar que a EJA emergiu como resposta da educação brasileira a um sistema social e econômico excludente. Inserem-se nos grupos excluídos e privados de ocupações fundamentais as pessoas em situação de pobreza, mulheres e crianças em situação de vulnerabilidade social e as pessoas em sofrimento psíquico. Estas últimas têm sido pouco ouvidas em pesquisas realizadas no Brasil, quando o assunto tratado diz respeito aos seus processos educacionais ${ }^{(6)}$.

Pesquisas brasileiras sobre caracterização do perfil clínico e sociodemográfico de usuários dos serviços de saúde mental, tipo CAPS, demonstraram o baixo nível de escolaridade e a baixa renda como variáveis relevantes para a análise das condições de vida das pessoas que procuram os serviços de saúde mental, além da expressiva presença feminina neste Serviço $^{(7-9)}$. Esses dados corroboram os apresentados pelo Instituto Brasileiro de Geografia e Estatística, sobre o quantitativo importante de pessoas analfabetas e menor média de anos de estudo, especialmente na região Nordeste ${ }^{(10)}$.

Em estudo recente, pesquisadores entrevistaram três pessoas analfabetas, usuárias de um CAPS. As autoras identificaram um histórico de trabalho precoce, que interrompeu a 
permanência na escola. Foram relatados ausência de suporte social e familiar, fatores socioeconômicos e estigma (preconceito) frente ao adoecimento mental $^{(6)}$. Cabe considerar que o aspecto da permanência nas instituições de ensino e o alcance de bons resultados está na estrutura e no suporte familiar. Os problemas familiares estão intimamente relacionados aos transtornos mentais, especificamente pela presença de sintomas de estresse, resultando em consequentes alterações do estado emocional. Estes elementos sugerem as fragilidades contextuais nas quais se inserem os sujeitos deste estudo, envolvidos em uma complexa malha de impasses durante as etapas de escolarização ${ }^{(11)}$.

Diante dessas fragilidades, há um delineamento de experiências na direção de um diálogo entre saúde mental e EJA, como a criação de salas de alfabetização em CAPS, geralmente vinculadas à Rede de Ensino Regular municipal, com o objetivo de criar um momento transitório de escolarização entre CAPS e escola regular ${ }^{(5)}$. Produzir cuidado em saúde mental perpassa pelo reconhecimento da escolarização como uma das estratégias de reabilitação psicossocial e contribui, sobretudo, para um processo inclusivo dos usuários dos CAPS.

Após essas considerações, abordando-se uma temática de tímida expressão na comunidade científica, acerca das propostas de educação para adultos usuários dos serviços de saúde mental, o presente estudo realizou a análise de narrativas dos usuários de um CAPS do tipo II no Distrito Federal. Considerou-se, para esta avaliação, as interfaces da escolarização no processo de autonomia e cuidado integralizado de pessoas em sofrimento psíquico.

O objetivo do estudo foi descrever e analisar a experiência desses usuários acerca de suas trajetórias de escolarização, assim como o resgate do ensino por meio da Educação de Jovens e Adultos.

\section{Método}

Este estudo caracteriza-se como uma pesquisa descritiva e analítica, de abordagem qualitativa. Esta opção de pesquisa reflete a compressão dos autores sobre a necessidade de aproximação com os múltiplos fatores da experiência dos educandos, que puderam tracejar as intermitências na escolarização e descrever a experiência da EJA no percurso dos desafios enfrentados. Em razão desses fatores, a pesquisa qualitativa mostrou-se como a mais adequada para o estudo do tema.

O local da pesquisa foi um Centro de Atenção Psicossocial II (CAPS) do Distrito Federal (DF), serviço de atenção à saúde, de base comunitária e territorial. Dentre as principais atividades desenvolvidas nesse espaço estão os atendimentos individuais, atendimentos às famílias, grupos e oficinas terapêuticas, projetos de geração de trabalho e renda, atividades de expressão e arte, ações em parceria com a rede intersetorial de serviços e atividades de participação comunitária.

Após aprovação pelo Comitê de Ética em Pesquisa (CEP) da Faculdade de Ceilândia (FCE) da Universidade de Brasília, por meio do Protocolo $\mathrm{n}^{\mathrm{o}}$ 2.513.823/2018, realizou-se um levantamento de dados sobre os usuários ativos que frequentaram ou estavam matriculados no EJA, com base no registro na ficha de acolhimento e consulta aos profissionais do Serviço em reunião de equipe multiprofissional.

Os participantes foram selecionados de acordo com os seguintes critérios de inclusão: usuários ativos do CAPS, com passagem pela EJA e usuários moradores das regiões de Ceilândia e Taguatinga, a maior demanda do CAPS. Excluíram-se os registros de usuários que estavam em pastas de arquivo morto do Serviço. No total, selecionaram-se quatro usuários da unidade, os quais foram convidados a participar da pesquisa, por meio de um contato telefônico. A proposta de participação foi efetivada em uma entrevista semiestruturada com duração de aproximadamente uma hora. Após o aceite dos participantes, foi agendado dia e horário por eles sugeridos, favorecendo a rotina dos acompanhamentos no CAPS, como condição facilitadora para a coleta do material.

Foi elaborado um roteiro de entrevista com as seguintes questões: Conte sobre o período inicial de sua escolarização e porque parou 
de estudar. O que the motivou a voltar a estudar? Como é a sua relação com a escola e os professores? Qual o seu sonho/desejo/interesse ao voltar a estudar?

As entrevistas foram gravadas e transcritas. A transcrição não ajustou as falas. O método de análise utilizado foi a análise de conteúdo temática $^{(12)}$. Como forma de rigor metodológico, as categorias temáticas foram analisadas por dois examinadores, a fim de chegar-se a um consenso sobre as categorias criadas para a análise e discussão. Os dados produzidos foram discutidos à luz dos referenciais políticos e educacionais no Brasil, e ainda do suporte social e familiar nos processos de aprendizagem e de gênero. Os participantes foram identificados na categorização como Educando 1, 2, 3 e 4.

\section{Resultados e Discussão}

A análise temática do conteúdo manifesto nas experiências descritas pelos usuários de saúde mental e alunos da EJA possibilitaram a emergência de quatro categorias de análise dos discursos, que serão descritas ao longo deste artigo, a saber: Categoria 1 - A ruptura primordial: Quem cuida e ensina antes da instituição escola assumir lugar? Categoria 2 - Desejar e sonhar: a saudade de querer ser; Categoria 3-O resgate do cuidado que ensina: a experiência de Educação de Jovens e Adultos; e Categoria 4 - Atravessamentos dos sintomas e processos de adoecimento.

\section{Categoria 1 - A ruptura primordial: Quem cuida e ensina antes da instituição escola assumir lugar?}

A convergência das trajetórias relatadas neste estudo revela os desencontros no processo de escolarização dos entrevistados e as interferências desse contexto no modo como percebem a si mesmos e posicionam-se socialmente. A infância é o período de maior demanda das funções de cuidado familiar. Este fator insere a instituição escolar como corresponsável no processo de formação cognitiva, moral, afetiva e social dos indivíduos. Além disso, é a interligação de todos esses aspectos que influencia as vivências de escolarização ${ }^{(13)}$.

As narrativas aqui apresentadas perpassam uma ruptura muito precoce nesta etapa, a qual sinaliza que, antes de a escola faltar para eles enquanto possibilidade, há violências e desamparos em etapas primitivas da experiência. Compreende-se, pela análise dessas histórias, que há uma série de fatores psicossociais de risco para desorganizações psíquicas e prejuízos de desenvolvimento socioafetivo. Uma vez que a família depara-se com dificuldades no cumprimento adequado das suas atividades mais básicas de socialização e de suporte aos seus membros, são criados contextos de vulnerabilidade ${ }^{(14)}$.

Há estímulos que podem influenciar o psiquismo de crianças e adolescentes de maneira somática e danosa, dentre os quais: ausência de relações parentais estáveis; falta de apoio no contexto social em que vivem; problemas econômicos, sociais ou pessoais; falta de cuidados maternos na infância; e agressividade parental. A ocorrência destes aspectos é frequente na fala dos participantes e abarca um conjunto de privações por eles identificadas na infância e projetadas nas necessidades do adulto, que possui um conjunto de interesses ligados a projetos de vida interrompidos ${ }^{(15)}$.

\begin{abstract}
Era uma escola simples, que tinha uma professora com nome de Rita. Ela me batia muito de palmatória. Bom, eu acho que fiquei até uns 10 anos, porque minha mãe me tirava da escola para me colocar na roça para trabalhar, para capinar. E eu trabalhava em jejum. Eu não era muito feliz, porque essa velha, que não era minha mãe, me batia muito. Era só parindo, e eu cuidando dos filhos dela. (Educando 1).

E se eu tivesse tido o apoio da igreja, eu já tinha terminado o segundo grau e já tinha feito a faculdade, né? Se tivesse o apoio da igreja, mas não tive o apoio da igreja e nem da minha familia. Sempre fui muito perseguido na minha família, porque meu pai sempre foi muito problemático, né? Aífui eu que criei os meus irmãos. Foi eu que
\end{abstract} criei os meus irmãos. (Educando 2).

Um dos desdobramentos do cuidado exercido pelas famílias é a inserção dos membros em uma comunidade escolar, que irá desempenhar práticas de ensino e socialização necessárias ao desenvolvimento socioemocional. No entanto, o modo de interação com as instituições familiares e de educação é influenciador da realização escolar ${ }^{(16)}$. Nos relatos apresentados, 
a família surge como ausente ou relacionada às situações de violência, o que inverte a sua lógica de proteção. Outra condição a se observar é que a configuração das escolas e os métodos de ensino relatados iniciaram-se em contexto rural, o que sugere maiores limitações na estrutura de ensino-aprendizagem.

Lá na fazenda da minha tia, que eu fui criado em fazenda, né? Era um grupo, né? Tinha um grupo lá, a minha prima que dava aula. Era roça. Era fazenda lá no Rio Grande do Norte. Eu aprendi a ler é... depois que eu fui alfabetizado... em jornal, né? (Educando 3).

A minha tia... Ela é minha mãe de coração. Foi ela que me ensinou a ler, a escovar os dentes, a cuidar da bigiene do meu corpo, que eu morava com ela, em um lugar com o nome Cumurupim. Ai eu cuidei, quando ela ganbou neném, do primeiro filho dela. (Educando 1).

Do mesmo modo que o ato de aprender consolida-se com as experiências afetivas, há uma ambivalência dos sentimentos de não pertencimento e nas fragilidades do sistema familiar que impediram a permanência na escola durante os estágios iniciais da vida. Coincide também, nos relatos, a função de cuidador delegada por essas famílias às crianças, ainda que demandassem a mesma condição para si, a imposta necessidade de subsistência, por meio do trabalho infantil, e a persistência em desenvolver habilidades que a escola ajudou a reconhecer e que necessitavam do investimento de um cuidador para ganhar sentido afetivo.

A precarização do cuidado apresentada nos depoimentos não foi capaz de impedir que os desejos e as aspirações infantis firmassem os papéis sociais e profissionais que desejaram ocupar, o que sugere o impulso de retorno à escola enquanto tentativa de ressignificar as possibilidades perdidas quando a formação escolar ficou pelo caminho. Cabe considerar que o "ensinar" surge nessas narrativas em uma relação estreita com o ato de cuidar e que a não conclusão do ensino formal é entendida como resposta à ausência de suporte afetivo familiar e social.

\section{Categoria 2-Desejar e sonhar: a saudade de querer ser}

Revisitar os sonhos do passado é tão comum quanto tocar as memórias de desamparo e frustração presentes nos relatos dos participantes. Os discursos constroem um processo avaliativo dos ideais do passado em torno de uma realidade que se distanciou dos resultados esperados, à medida que as dificuldades impuseram-se. Ainda assim, adequações desses anseios foram se estruturando e reconduzindo novas tentativas de realização pessoal. O meu sonho é que eu queria ser aeromoça! Que era pra
mim passar em casa sabe? Quando chegasse de viagem...
Só jogar comida para os filhos e eles que se virassem! Esse
aí é meu sonbo! (Educando 1).
Porque, eu sempre tive o sonho de fazer faculdade, né?
Aí eu pensei: Se for de Deus, se for certo terminar o en-
sino médio, ai eu vou fazer um curso superior né? Que
é nutrição! Tinha esse pensamento, né? Mas acontece
que eu não tive apoio, né? Não posso contar com minha
família. (Educando 2).

Ai, pra chegar essas duas profissões que eu tenbo, eu ralei muito, entendeu? Tive que trabalhar de ajudante, pra ir aprendendo, tive que fazer curso pra aprender. Peguei o curso pela internet, pra fazer os tipos de trabalbo, entendeu? Pra fazer elétrica, fazer hidráulica. Se eu tivesse meus estudos, se eu voltar a fazer é... e eu continuar a estudar, eu vou fazer engenharia! (Educando 3).

O ensino superior é apresentado como o sonho de conquistar um lugar de reconhecimento, tornar-se visível e, assim, assumir uma identidade que lhes assegure em meio às fragilidades apontadas nas relações familiares, bem como das consequências da privação de outros espaços de proteção social. Observa-se, sob a perspectiva de gênero, que, além do sonho de ter uma formação profissional, há, no desejo feminino, a necessidade de abrir mão da dedicação exclusiva em suas funções maternas e do lar, para poder exercer a autonomia por meio da relação com o trabalho.

O direito à educação é uma pauta antiga e complexa para as mulheres. Para educadores da EJA, há um desafio em torno de uma organização curricular capaz de dialogar com os saberes e as práticas produzidos por essas mulheres fora da escola. Esse tipo de reflexão precisa considerar as interfaces de relação entre classe, gênero, raça e experiências de trabalho, porque esses aspectos frequentemente revelam existências marcadas pela exclusão social ${ }^{(17)}$. Ainda que os educandos considerem o apoio da família um incentivo indispensável para o 
alcance da formação superior, foi com base nas frustrações vividas que outras possibilidades de trabalho construíram-se, dentre as quais, a formação técnica e empírica de atividades laborais, além do desempenho de papéis sociais apoiados em novas perspectivas. Nesse mesmo cenário, a retomada dos estudos vem resgatar as memórias e mobilizar afetos para a condução de um novo caminho na escolarização do adulto, o que permite a construção de novos objetivos e escolhas.

\section{Categoria 3-O resgate do cuidado que ensina: a experiência de Educação de Jovens e Adultos}

A determinação de resgatar oportunidades e a construção de novos vínculos de cuidado reorientaram, para esses educandos, o reencontro com a experiência de escolarização. Nesse momento, é indispensável considerar que se trata de biografias em movimento, as quais assumiram representações e valores transformados pelas vivências, em que novas situações de reconhecimento pessoal e social foram convertidas na busca pela EJA. Eu gosto muito de escola, né? Porque eu era esforçado!
Eu conseguia copiar tudo, apesar de ter passado muitos
anos sem estudar. E aí, o que eu não dava conta, eu fazia
na sala de recurso. Com a ajuda dos professores da sala
de recurso, eu estava conseguindo copiar, conseguindo
aprender, né? Fazer os trabalbos. (Educando 2).

Pra mim, ficar mais atualizado ou com meu curso de computador, né, também, que eu fiz para ficar melhor, ter uma qualidade de vida melhor, entendeu? Pra mim tudo é fundamental. Todos eles são fundamental, porque são professores qualificados, são professores bons que me ajudam bastante. Eu sou muito feliz na escola onde eu tô. (Educando 4).

Ah, era bom, né! Eu gosto muito de... de ler entendeu? Mas com problema na visão é... parei de ler, entendeu? E escrever... eu também gosto de escrever! Eu comprei livro, esses caça-palavra, entendeu? Eu vou usando as palavras tudinho. Depois eu passo para o caderno. (Educando 3).

Observa-se que, mais uma vez, a entrada da escolarização precisa ajustar-se, face a identidade de gênero, de modo que, nesta narrativa, a educanda aponta para uma subjetividade construída em torno do cuidado familiar e dos afazeres domésticos. Afirma que, atualmente, há ainda o desafio de lidar com o cansaço das tarefas domésticas, o que resulta em um período mais restrito para os estudos.

Porque, quando eu quero alguma coisa, eu luto até conseguir. Porque é bom estudar. Mas aqui, no Centro de Ensino 6, era melhor, porque tinha aula de violão... tinha aula de arte. Eu tenho muito é cansaço! Só falta tempo para estudar, porque eu lavo, eu passo, eu cozinho... (Educando 1).

É indissociável, para as estudantes do EJA, conciliar as atividades escolares com o trabalho doméstico, os compromissos familiares, o trabalho remunerado, entre outras práticas de cuidado e responsabilidades com os membros da família. São as experiências de vida e as possibilidades construídas na representação social do feminino que provocam as adaptações nessas mulheres, para exercer o direito à educação. Assim, é válido observar, nesse transcurso, uma resposta de resistência e luta pelas conquistas femininas ${ }^{(17)}$.

As motivações para o retorno à escolarização consideram a entrada de novos agentes de cuidado, a busca pela autonomia do conhecimento e o prazer em desenvolver habilidades e expressão pela arte. O ato de estudar é visto como uma coisa boa, que oferece prazer, bem-estar. Ambos, educandos 1 e 3, descreveram como se mobilizavam entre as estratégias de ensino para conhecer a leitura e a escrita em um novo processo de aprendizagem, de profissionalização e despertar de consciência para um mundo vivo de sentidos.

Me matriculei no EJA foi através da associação dos idosos. A presidenta é como se fosse uma mãe pra mim. Ela me acolbe há 7 anos lá ubum. A [...] tem me ajudado muito. Ela me tirou do fundo do poço. Eu tive um problema muito sério, e ela me ajudou muito! (Educando 4).

Eles explicam tudo direitinho, dá gosto! Eu gosto, nossa como eu gosto! São... o professor [...] a professora [...] $e$ a professora [...] que é da aula de matemática que é na sexta. (Educando 1).

A gente tem ajuda dos outros. Quem entende mais e tem mais é... conbecimento na leitura, entendeu? Aí a gente pede ajuda pra eles. (Educando 3).

O desenvolvimento, enquanto sujeito que transita em relações de suporte mútuo, configura-se no apoio coletivo em sala de aula para o desempenho de tarefas. Além disso, denota a função social dos programas educativos 
desenvolvidos pelo EJA enquanto ferramentas de enfrentamento para os desafios e as situações de desamparo por eles vivenciadas. Cabe considerar que a necessidade de suporte nas relações pessoais para o investimento na aprendizagem aparece como demanda contínua e atemporal, o que permite que os participantes do EJA resgatem essas demandas ainda hoje e construam novas possibilidades de realização.

\section{Categoria 4-Atravessamentos dos sintomas e processos de adoecimento}

Quando se toma o processo de adoecimento como foco de análise, é inevitável destacar a importância de diálogos e negociações efetivas em torno das propostas de inclusão escolar para pessoas com agravos de saúde mental e complexidades clínicas associadas. Apesar dos princípios normativos que garantem o bom funcionamento de uma instituição, é preciso pensá-la em torno das particularidades de seus integrantes, para que se garanta uma efetiva participação e o delineamento de um espelho de intervenções sobre as demandas apresentadas.

Dentre as condições inerentes aos transtornos mentais que exercem influência nas propostas de ensino-aprendizagem, cabe considerar a presença de déficits cognitivos, o efeito das medicações de uso continuado, as oscilações dos estados de humor, as disfunções da sensopercepção, bem como os hábitos e rituais característicos dos diagnósticos psiquiátricos, como expressa a fala a seguir.

Eu tomo remédio pra dormir. Eu tomo injeção Haldol. Eu tô tomando comprimido agora, porque eu estava com pedra na vesícula. Eu tô tomando remédio, que o médico passou um bocado de remédio pra mim tomar, estava sentindo dor entendeu? (Educando 3).

Essa realidade demanda a oferta de uma rede intersetorial de serviços, que garanta a articulação de políticas assistenciais, a fim de que a reabilitação, o cuidado e a atenção psicossocial se deem em todos os espaços que conferem os direitos sociais básicos, dentre os quais o direito à educação ${ }^{(18)}$. Não se trata, portanto, de uma mera inserção desses usuários na EJA, mas da necessidade da sua inclusão (permanência), por meio do cuidado contínuo e acompanhado pelos diversos atores: profissionais da rede de suporte social, família e comunidade.

Porque, aqui no CAPS, eu tenho apoio, né? Estou fazendo tratamento direitinho. Ai eu também tenho, além da esquizofrenia, também tenho uma doença com o nome de TOC. Eu demoro muito para lavar as mãos, barbear, escovar os dentes, tomar banho. Demoro muito. (Educando 2).

Embora as determinações sejam múltiplas, as interrupções no processo de escolarização surgem em meio às experiências de violência $e$ ciclos de adoecimentos, sejam eles transitórios ou permanentes, mas que impõem obstáculos ao cumprimento de suas obrigações enquanto estudantes. Identifica-se que, para além das características dos transtornos psiquiátricos, há comorbidades clínicas que impactam na saúde dos entrevistados e, em algum momento, foram responsáveis por impedir o acesso e a permanência no período letivo escolar.

Eu percebi esse problema uns 3 anos atrás. Comecei a perder a visão, entendeu? Eu enxergava muito pouco do olbo direito. Eu vejo só o vulto, entendeu? Do olbo direito, eu não enxergo nada! Agora, do olho esquerdo, praticamente eu só enxergo 60\% também. A vista também tá embaraçada. (Educando 3).

Agora eu estou focando na minha saúde, né? Porque eu sou diabético, as minhas pernas estavam inchando. Eu tive um problema sério nessa minha perna $e$ agora eu estou melhorando, que eu estou voltando para os tratamentos. O médico dos pés estava fazendo pra mim. (Educando 4).

Outro aspecto diz respeito ao formato de aprisionamento na relação conjugal, manifesto pelo relato que se segue, e no sofrimento relacionado às atribuições da maternidade precoce. Esse processo conduziu a frustrações e afetos negativos ao longo das experiências de vida da educanda, de maneira que esta protesta, ao longo da narrativa, a apropriação de um direito, o de estudar e, com isso, ter a liberdade que outrora lhe foi negada.

Como eu gostava de estudar! Mas, com 3 anos que eu estava aqui, meu marido me captou no caminho da escola, e meu pai me obrigou a casar com ele, que tinha 21 anos. Aí eu tô casada na marra. Foi o dia mais infeliz da minha vida [...] Eu fiquei chorando com um filbo nos braços. Ia fazer um ano e eu já estava esperando outro, depois de ele ter me batido bastante! Eles não me deixaram estudar, conversar com ninguém. Eu não podia nem ficar na porta, que ele já me batia. (Educando 1). 
Esse recurso de enfrentamento inseriu o EJA como um horizonte de escolhas e provocou mudança nas relações de opressão a que foi submetida pelo casamento, muito embora, nas categorias anteriores, tenha ficado evidente que as relações de gênero demandaram e ainda demandam esforços maiores para cumprir seus objetivos. Compreende-se, assim, que há um patrimônio pessoal, isto é, uma bagagem de experiência que se depara com múltiplos contextos, os quais geram e demandam processos de aprendizagem diversificados.

É necessário superar a ideia de que a educação faz-se por meio de transferência de conhecimento, com práticas de ensino uniformes ou educação bancária ${ }^{(19-20)}$. Esse pressuposto perde lugar para a utilização de situações comunicativas que permitem retratar, por meio da escrita, da leitura e da fala, o mundo social. Nesta proposta é indispensável a revisão dos papéis dos educadores para atores investigativos, criativos e reflexivos de suas práticas. Estas características permitem a elaboração de projetos pedagógicos ampliados e inclusivos, os quais devem estabelecer diálogos acerca dos aspectos socioeconômicos, processos de saúde-doença, histórico de escolarização, valores e aspectos culturais dos educandos.

Observa-se, nas limitações deste estudo, que a condição de adoecimento mental é multifatorial. Foi considerada, para esta análise, a perspectiva dos usuários implicados na própria experiência, o que limita a compreensão à ótica centrada no discurso do sujeito. Além disso, a coleta deu-se na unidade em que se realiza o tratamento em saúde mental, o que pode ter interferido no modo como desejam ser identificados e as representações inerentes àquele espaço.

\section{Conclusão}

Os eixos de análise aqui apresentados evidenciam que a aprendizagem se dá em um processo de mediação pelo cuidado. É o investimento afetivo, propiciado pelos profissionais de saúde, da educação, da família e da comunidade, o fator condicionante para o início e o transcurso das motivações ligadas aos objetivos de formação pessoal e profissional desses usuários. No entanto, as faltas apontadas pelos participantes durante o desenvolvimento infantil, além do contexto socioeconômico e de vulnerabilidades aos quais pertencem, demonstraram as rupturas e perdas em seus projetos de vida, incluindo a educação.

A proposta de inclusão social e de resgate da autonomia, bem como o aprimoramento das relações interpessoais obteve, no encontro com o EJA, condições férteis para construir vínculos de conhecimento e a experimentação de um novo ambiente social com base em suas realidades. Assim, a mudança na lógica de cuidado em saúde mental precisa ser um projeto social e coletivo, dado que o modelo de atenção psicossocial acontece na intersetorialidade de programas, ações e serviços para conferir a integralidade de assistência.

É predominante, na argumentação dos participantes, no que tange às suas interrupções com o contato escolar, que a ausência de suporte social e familiar impediu-os de alcançar suas metas iniciais de realização, as quais precisaram ser adaptadas ou substituídas. Outra percepção diz respeito aos papéis sociais de gênero, que surgem como barreiras e limitações durante o percurso de escolarização, marcado pela divisão entre tarefas domésticas e de cuidado familiar, o que prejudicou o rendimento escolar e a noção deste enquanto prioridade.

Trata-se de tomar como foco o educando e o usuário, pois são eles que oferecem aos serviços um patrimônio existencial transformado pelos determinantes sociais, características do adoecimento mental, da organização familiar de origem e da rede de suporte social à qual pertencem. É nisso que se constitui o desafio dos professores do EJA, os quais precisam trabalhar com a heterogeneidade apresentada, a fim de construir perspectivas de cuidado e ensino como meio de oportunizar processos educativos promotores de conhecimentos aplicados ao contexto.

Sugere-se que mais estudos busquem correlações nos processos de escolarização de usuários de saúde mental na EJA, para maior 
aprofundamento das hipóteses aqui lançadas. Espera-se que estes resultados orientem condutas entre os profissionais de saúde e educação, bem como aspectos da dinâmica institucional dos serviços que trabalham com este tema.

\section{Colaborações:}

1 - concepção, projeto, análise e interpretação dos dados: Ioneide de Oliveira Campos e Yasmim Bezerra Magalhães;

2 - redação do artigo e revisão crítica relevante do conteúdo intelectual: Ioneide de Oliveira Campos e Yasmim Bezerra Magalhães;

3 - aprovação final da versão a ser publicada: Ioneide de Oliveira Campos e Yasmim Bezerra Magalhães.

\section{Agradecimento:}

Fundação de Apoio à Pesquisa do Distrito Federal, Brasília, Brasil.

\section{Referências}

1. Amarante P, Torre EHG. Loucura e diversidade cultural: inovação e ruptura nas experiências de arte e cultura da Reforma Psiquiátrica e do campo da Saúde Mental no Brasil. Interface (Botucatu). 2017;21(63):763-74. DOI: https://doi. org/10.1590/1807-57622016.0881

2. AmaranteP, NunesMO.Areforma psiquiátricanoSUS e a luta por uma sociedade sem manicômios. Ciênc Saúde Coletiva. 2018;23(6):2067-74. DOI: https:// doi.org/10.1590/1413-81232018236.07082018

3. Saraceno B. Libertando identidades: da reabilitação psicossocial à cidadania possível. Rio de Janeiro: Instituto Franco Basaglia/Te Cora; 1999.

4. Vasconcelos MGF, Jorge MG, Catrib AMF, Bezerra IC, Franco TB. Projeto terapêutico em Saúde Mental: práticas e processos nas dimensões constituintes da atenção psicossocial. Interface (Botucatu). 2016:20(57):313-23. DOI: https://doi. org/10.1590/1807-57622015.0231

5. Silva MM. Desafios intersetoriais: possibilidades de diálogos entre a saúde mental e a Educação de Jovens e Adultos. Curitiba: Appris; 2017.
6. Campos IO, Magalhães YB. Analfabetismo e Saúde Mental: o discurso de usuários de um Centro de Atenção Psicossocial. Rev FSA [Internet]. 2019 [cited 2019 Nov 23];16(4):151-65. Available from: http://www4.fsanet.com.br/revista/index. $\mathrm{php} / \mathrm{fsa} /$ article/view/1838

7. Campos IO, Ramalho WM, Zanello V. Saúde mental e gênero: o perfil sociodemográfico de pacientes em um centro de atenção psicossocial. Estud Psicol. 2017 mar;22(1):68-77. DOI: http:// dx.doi.org/10.22491/1678-4669.20170008

8. Paula CTC. Profile epidemiological of the users of the Psychosocial Care Center in the city of Recife. Cad Bras Saúde Mental. 2010;2(4-5):94-106. DOI: 10.11606/issn.1806-6976.smad.2020.156687

9. Barbosa CG, Meira PRM, Nery JS, Gondim BB. Epidemiological profile of the users of a Psychosocial Care Center. SMAD-Rev Eletrônica Saúde Mental Álcool Drog. 2020;16(1):1-8. DOI: 10.11606/issn.1806-6976.smad.2020.156687

10. Instituto Brasileiro de Geografia e Estatística. Coordenação de Trabalho e Rendimento. Pesquisa nacional por amostra de domicílios: síntese de indicadores 2015. Rio de Janeiro; 2016.

11. Mombelli MA, Costa JB, Marcon SS, Moura CB. Estrutura e suporte familiar como fatores de risco de stress infantil. Estud psicol. 2011;28(3):327-35. DOI: https://doi.org/10.1590/ S0103-166X2011000300004

12. Bardin L. Análise de conteúdo. 6a ed. Lisboa: Edições 70; 2016.

13. Mendes ECCS, Brunoni D. Competência em leitura: interface entre contextos psicossocial, familiar e escolar [online]. São Paulo: Mackenzie; 2015. Saberes em tese collection, v. 11.

14. Piccolo LR, Falceto OG, Fernandes CL, Levandowski DC, Oliveira RG, Salles JF. Variáveis psicossociais e desempenho em leitura de crianças de baixo nível socioeconômico. Psic Teor Pesq. 2012:28(4):389-98. DOI: https://doi.org/10.1590/ S0102-37722012000400004

15. Pires TO. Fatores psicossociais relacionados ao transtorno de déficit de atenção/hiperatividade em escolares do Município de São Gonçalo [dissertação]. Rio de Janeiro: Escola Nacional de Saúde Pública Sergio Arouca; 2011.

16. Petrucci GW, Borsa JC, Koller SH. A família e a escola no desenvolvimento socioemocional na 
infância. Temas Psicol. 2016;24(2):391-402. DOI: http://dx.doi.org/10.9788/TP2016.2-01Pt

17. Godinho ACF, Fischer MCB. Escola, trabalho e gênero: uma experiência da Educação de Jovens e Adultos na rede pública de ensino de Porto Alegre. Educ rev. 2019;35(75):335-54. DOI: https:// doi.org/10.1590/0104-4060.62199

18. Salles MM, Barros S. Representações sociais de usuários de um Centro de Atenção Psicossocial e pessoas de sua rede sobre doença mental e inclusão social. Saúde soc. 2013;22(4):1059-107. DOI: https://doi.org/10.1590/S0104-12902013000400009
19. Marques S, Oliveira T. Educação, ensino e docência: reflexões e perspectivas. Rev Reflexão Ação [Internet]. 2016 [cited 2019 Dec15];24(3):189-211.Availablefrom:https://online. unisc.br/seer/index.php/reflex/article/view/7346

20. Freire P. Pedagogia da autonomia: saberes necessários à prática educativa. São Paulo: Paz e Terra; 2011.

Recebido: 19 de dezembro de 2019

Aprovado: 11 de julho de 2020

Publicado: 5 de outubro de 2020

A Revista Baiana de Enfermagem utiliza a Licença Creative Commons - Atribuição-NãoComercial 4.0 Internacional.

https://creativecommons.org/licenses/by-nc/4.0/

Este artigo é de acesso aberto distribuído sob os termos da Licença Creative Commons (CC BY-NC).

Esta licença permite que outros remixem, adaptem e criem a partir do seu trabalho para fins não comerciais. Embora os novos trabalhos tenham de lhe atribuir o devido crédito e não possam ser usados para fins comerciais, os usuários não têm de licenciar esses trabalhos derivados sob os mesmos termos. 